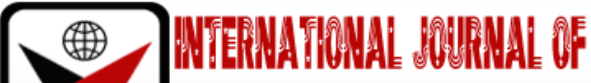

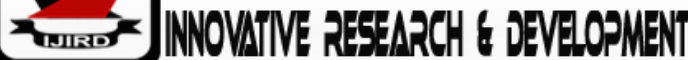

ISSN 2278 - 0211 (Online)

\section{Challenges Faced by Schools as They Engage Adolescents in Sexual Health Education in an Effort to Reduce Early Teenage Pregnancies in Mzilikazi District, Zimbabwe}

Sibusisiwe Ncube
Part time Lecturer, Department of Higher Education, Zimbabwe Open University, Zimbabwe
Onias Mafa
Professor, Department of Higher Degrees, Zimbabwe Open University, Zimbabwe

\begin{abstract}
:
The continuos rise in number of teenage pregnancies has become a major public health issue which has the potential to erode all the gains achieved in trying to empower the girl child for self sustainance.The study through 'health risk' sensitive lenses evaluated the challenges faced in trying to implement Sexual Health Education Programmes in reducing early teenage pregnancies in Mzilikazi District in Bulawayo metropolitan province.Literature review was conducted from primary and secondary data sources. while journal reports, textbooks and various internet websites were utilised as secondary data sources. The Social Learning Theory (SLT), was selected based on four key variables relevant to teenage physical growth and mental development. The variables are interaction and participation, empowerment and adaptation to the environment in which they live.The study adopted a case study approach and employed a qualitative methodology of enquiry based on an interpretivist philosophical paradigm. The idea was to build a holistic picture of lived experiences by stakeholders through drawing inferences from selected research participants. Convenience sampling technique was adopted in the selection of the research participants owing to the sensitivity of the subject matter under discussion. The sample size was 70 and all participants freely accepted the invitation without being induced or being enticed to partake in the study. To ensure that captured data fully presented views and perceptions of participants, four data collection techniques were used which are Questionnaires, Focus Group Discussions (FGD), Interviews and Data Analysis. Data were analysed and synthesised through the use of Word Query and coding. Captured audio/voice responses were transcribed and later slotted into emerging themes. The study established that, few teachers trained in the subject area also contributed to the ineffective engagement of teenagers in schools resulting in some learners boycotting lessons linked to Sexual Health Education. The situation was worsened by the fact that some teachers were shy to engage teenagers on comprehensive Sexual Health Education preferring to dwell more on the abstinence approach. The study recommends that Ministry of Primary and Secondary Education should facilitate human capital development programmes for capacity building, in this respect, teachers and School heads can be called to attend refresher courses or workshops to receive updates on trends of teenage pregnancies and challenges emerging due to teenage pregnancies. There is need for awareness programmes on early teenage pregnancies spearheaded by teachers and learners. Learners can also be given a chance to interact with single mothers who fell pregnant and are regretting the missed opportunities forgone in learning, this helps teenagers to know and accept the realities of life.
\end{abstract}

Keywords: Sexual health education, teenage pregnancies

\section{Introduction}

In Zimbabwe, the Demographic Health Survey (ZDHS) (2011) reports that 24\% of young women of ages between 15 and 19 years have begun child bearing. The report further reveals shocking statistics as it points out that, among the women who are sexually active, there is 1 in 5 women who have started indulging in sexual activities by sheer force or manipulation.Therefore, there is need to examine the challenges bedevelling the effective teaching of Sexual Health Education in schools, and come up with mitigating strategies. Another startling revelation from the ZDHS (2011) is that above $6 \%$ percent of girls and $2 \%$ of boys have started engaging in sexual intercourse by the age of 15 years. This has prompted various stakeholders to initiate programmes aimed at tackling the menace of early teenage pregnancies. Most notable programmes on Sexual Health Education appear to be based on life skills targeting girls and boys between the ages of 12-19 years. According to WHO (1993), life skills are methods for adaptive and affirmative behaviour that enhance people to focus effectively on their needs and challenges they come across in everyday life. Debates have ensued following the adoption of Sexual Health Education in schools, high birth and death rates have prompted various studies on the subject (Kirby 2001; 2008). Since its adoption, there has been a major transformation on sexuality education in schools, as initial studies looked on whether to teach sexuality education or not, while recent studies have shifted focus to the type of 
Sexual Education best for learners .Initially Sexual Health Education was integrated into numerous obligatory educational programmes strictly as part of Biology lessons in primary, secondary education and, later on in professional programmes which are related to general health issues (Ponzetti, 2015). Laski (2015) hints that Sexual Health Education has been accepted globally as proved by the United Nations (UN) General Secretary's Global Strategy for Women and Children's Health. It mainly focuses on teenage health in the post-2008. It also looks at the sustainable development goals agenda.

\section{Statement of the Problem}

Early teenage pregnancies have prompted various stakeholders to initiate programmes aimed at tackling this menace, as a result challenges have ensued following the adoption of Sexual Health Education in schools. Therefore, there is need to examine the challenges bedevelling the effective teaching of Sexual Health Education in schools, and come up with mitigating strategies.

\section{Research Questions}

- What are the challenges faced by schools as they engage adolescents in Sexual Health Education in an effort to reduce early teenage pregnancies in Mzilikazi District?

- How do challenges faced by schools as they engage teenagers affect the effective implementation of Sexual Health Programme?

- How can the challenges faced in the implementation of sexual health programmes be addressed?

\section{Review of Related Literature}

\subsection{Conceptual Framework}

It follows that, the schools, society, and parents are key in moulding teenage behaviour. Thus it is envisaged that parental guidance and school-based education programmes can address issues to do with teenage sexuality, unplanned teenagepregnancies, and sexually transmitted diseases. Some key indicators from Non Governmental Organisations (NGOs) and schools can be used to measure the successes of these programmes. To show that there are improvements and successes in these programmes, teenage pregnancies and STIs must be seen declining.

\subsection{Challenges Faced by Schools Involved in Sexual Health Education}

Problems and limitations at the disposal of schools when it comes to the implementation of Sexual Health Education are best understood after learning the basic requirements for a successful Sexual Health Education programme as presented by Kirby (1995, 2001, and 2002) and Kirby, Laris, and Rolleri (2005). It is from these set requirements that a fair assessment of performance and challenges was drawn.

Kirby (2002) cited in Smyle, Matika-Tyndale, and Boyd (2008) presented the following basic requirements for schoolbased Sexual Health Education:

- Sustainable development and training for those responsible in the administration of the initiative ;

- Adequate classroom time slots (minimum of an hour long instruction);

- A theoretically grounded approach which includes the theories of social learning, social influence or reasoned action;

- Usage of elicitation research, as well as holistic, age-appropriate teaching methods and culturally specific behavioural goals, to both, ascertain learner characteristics or needs and to allow for learners to personalise some information;

- A goal towards decreasing particular risky practives that could cause unplanned pregnancy or STI/HIV infection;

- Frequent and consistent reinforcement of personal values and peer norms related to sexual limit setting and usage of contraception;

- Interactive exercises to communicate health risks and how to get rid of them;

- Discussion and strategies that look at the pressures associated to teenage sexual behaviour;

- Integration of information, motivation and communication/negotiation skills necessary to improve the self esteem and sexual agency;

- Opportunities to practice communication and negotiation skills necessary for sexual limit setting, negotiating contraception use, as well as to increase confidence and sexual agency.

Added to the list by Kirby, Laris and Rolleri (2005) are:(a) the participation of individuals from different backgrounds in sex and HIV education in the improvement of the curriculum; (b) prior examination of the important needs of the targeted groups; (c) adopting the protective elements affecting behaviours, including knowledge, perceived risks, values, attitudes, perceptions, and self-efficacy; and (d) ensuring that there is support from appropriate stakeholders such as local authorities in the health sector, and community institutions. This study notes with concern the exclusion of culture from all the recommended points mentioned by various scholars.

An analysis by UNAIDS (2014) clearly indicated the major problems and unequal progress in many key Sexual Health Education indicators within the sub-Saharan African countries. Gender inequalities are being practised with little evidence of varieties in gaps in age at sexual onset and first marriage, leading to teenage girls remaining more vulnerable to poor sexual health outcomes and diseases. It has been very clear that there are persistent inequalities in indicators these being education, urban-rural residence and economic status of the household which need more attention so as to 
make progress towards the goal of equity as part of the SDGs and universal health coverage. These recurrent inequalities suggest the need for diverse approaches which address the structural issues underlying poor Sexual Health Educationsuch as education, poverty, gender-based violence, gender equality and poor economic opportunities amongst nations (Rasanathan, Damji, Atsbeha 2015).

UNDPES (2019) shows the differences between the two sub regions where the studies were done in sub-Saharan Africa and were used in the analyses, the results showed that West and Central Africa were lagging behind in teenage health education, whereas Eastern and Southern African countries were suffering from a more dangerous and aggressive HIV epidemic among teenagers. Teenage girls in West and Central Africa had higher chances to initiate sex, get married and give birth earlier and have lower family planning usage, compared with those in Eastern and Southern Africa. Whilst when compared to boys, they delay sexual initiation and marriage are generally later in West and Central Africa compared with similar age group of boys in Eastern and Southern Africa, leading to a longer period of sex before marriage in West and Central African countries. Even though there is a likelihood to identify general regional flows, there were clear cut country differences within the sub regions which needed further studies and have implications for efforts to reduce inequalities in Sexual Health Education (United Nations, Department of Economic and Social Affairs 2019).

\subsection{Ownership and Control of the Sexual Health Education Programmes}

In the USA, Finland as well as Canada, the governments have partnered with non-governmental organisations and have taken proactive steps to ensure programme success (Kirby 2001, Goldstein, 2017). This approach ensured broad stakeholder participation. The same approach has been adopted in Africa, countries like Malawi, Tanzania, South Africa and Zimbabwe where national governments have also partnered with non-governmental organisations to encourage Sexual Health Education in schools and communities. Mukoma (2009) butresses the above notion as he hinted that in Zimbabwe, sexual health programmes in schools are implemented through a collaboration between Ministry of Education, Sport and Culture and UNICEF. Successful initiation of sexuality and Sexual Health Education is not spared from problems and limitations. Seabrook (2000) and Emmanuel (2015) notes that there are a number of problems with programme implementation. The authors bemoan that although the sexual health programme has been compulsory in most countries, coverage is low and there are also widespread problems of ownership and resistance. In Zimbabwe, Seabrook (2000) noted that Sexual Health Education programme became compulsory in 1993 and was a top-down approach. The author (Seabrook) bemoans the radical nature of the programme in Zimbabwe as it ignores the participatory nature required under the life skills approach.

\subsubsection{Shortage of Human and Technical Knowledge}

The African nations have subscribed to the International Conference on Population and Development(ICPD) and renewed their commitment on the occasion of Cairo conference, as well as in a number of regional instruments, especially those developed by the African Union, many policies are lagging behind in as far as the expectations of all the participants (United Nations, Department of Economic and Social Affairs 2018).One of the challenges they are facing in as far as policy formulation is concerned is the shortage of adequate human and technical knowledge to monitor progress in the implementation of the formulated objectives. The areas of concern include that of data collection and analysis and the shortage of indicators and benchmarks and the quasi absence of Sexual Health Education management information systems in many countries. It is therefore deemed necessary to change laws so as to match the commitments made, especially in the areas of Sexual Health Education, HIV/AIDS and Teenagers. To add on to the above, there is a need to build and improve the capacity of health care providers for the successful implementation of these commitments (Sexual and Reproductive Health and Rights, 2018).

\subsubsection{Technology Influenceand Wealth Related Inequalities}

With the invention of technology, the world has been turned into a global village with events happening at one corner of the globe also being experienced in other parts of the world. With this rapidly changing environment, Giami, Ohlrichs, Quilliam, Wellings (2006) doubt that Sexuality Health Education adequately offers support to the young people of today where, peer pressure and a continuous storm of distorted media images influence and shape their emerging sexuality. Within this continuous variation of contexts, there are changes to how teenagers are perceived by the older generation as well as changes to their needs for information and skills to learn to negotiate their sexuality. However, scholars like Wilcott (2011) argue that technology can be used positively to impart good behaviour to adolescents.

While there are very few studies done in different countries to examine socioeconomic differences in Sexual Health Education programmes in sub-Saharan Africa, there is clear evidence of a wealth differences for a number of indicators such as child marrieages, age at first birth and and access to contraceptive.This is a good indicator that poorer teenagers face serious barriers in realising their reproductive health and rights (Rani and Lule, 2004). The data from the DHS surveys from 33 countries provided more evidence of large disparities in Sexual Health Education by wealth quintile. Compared with teenage girls from the richest wealth quintile, teenage girls from the poorest wealth quintile had their first sex 2.2 years earlier, married 4.6 years earlier and gave birth 4.1 years earlier. Boys in both rich quintiles started sex at the same age, but those in the poorest homes married 4.3 years earlier than those in the richest homes. HIV prevalence was higher among both sexes in the richest quintiles among 15-24 years in both regions and most countries. In a nutshell, the wealth-related differences are even larger than for education and place of residence (Rasanathan ,Damji , Atsbeha, 2015). The findings revealed that differences for first sex, marriage and childbearing between the poorest and richest nations increased except for marriage among males. The median age at first birth had increased by 0.8 and 1.3 years among those from urban and wealthiest families, respectively, during the period 2004-2015. 


\subsubsection{Lack of Sexual Health Education Teaching Skills among Teachers}

Social Learning Theory by Bandura has the element of empowerment and self-efficacy, which means a person's confidence in acting in a certain manner, performing a particular behaviour with the hope of achieving a certain positive goal (Bandura, 1977). He argued that it is more likely for an individual to put into practice socially learned behaviours if he or believes they will yield positive results. The two concepts of self-efficacy and empowerment are more readily implemented to the claim education is beneficial to those that are proactively involved in engaging learners.

The need for a high level of self-efficacy among teachers' educators is crucial if they are to carry out interventions on teenagers. Klein et al (1994) in their study found that people who volunteered to become peer educators had done so on the basis that they had developed self-confidence from grooming or past experiences on the subject. This would suggest that for teachers in Mzilikazi District to fairly engage learners on Sexual Health Education they must first possess the necessary skills and qualities which they can impart to others without difficulty.

\subsubsection{Abuse of Learners by Teachers}

Ross et al (2010) arguethat though the Sexual Health Education programmes have registered much success, it seems that the major threat to the programme emanates from the context of delivery in the school system following findings from the MEMA Kwa Vijana team. The team reported that the school-based intervention strategies were being enacted in a context of massive gender and status power variations amongst the teachers and learners. This created an environment for rape, economic exploitation, beating of learners and other forms of abuse thus severely undermining positive progress from the initiative.

\subsubsection{Objection to the Curricular by Parents}

There seems to be a great contradiction in the way parents in high income nations understand the importance of Sexual Health Education programmes in schools when put in comparison to low income nations. In a study conducted by the National School Nurses Association (NASN) (2012) in the USA on acceptance of the Sexual Health Education curriculum, the majority of parents and learners supported education about human sexuality in schools. This is also seconded in the Kaiser Family Foundation and Harvard's Kennedy School of Government (2004) reports which indicated that the significant majority of Americans polls concurred that Sexual Health Education should be taught in schools. Furthermore, the majority believed that the topic of sexual orientation was supposed be included in sexuality education programmes.

In Fiji, resistance and reluctance about breaking known taboos related to teenage sexuality and addressing teenage pregnancies directly and openly are rarely mentioned by parents. Teenage sexual health in Fiji is up to date a sensitive and controversial topic. Sexual Health Education was first introduced in 1985 and reintroduced in 2007-2008 due to concerns over teenage pregnancy and STIs among teenagers (Naz, 2014).Unfortunately, despite starting a sex education programme in schools, unwanted teenage pregnancy, STIs, and HIV continued to rise. The study investigated parents' understanding and aspiration towards sex education in public secondary schools in Fiji as well as parents' understanding of major areas in Sexual Health Education and hinderances to the delivery of Sexual Health Education in the high school.

\section{Research Methodology and Design}

Qualitative research enabled the researchers to investigate issues around Sexual Health Education and its relevance to reducing early teenage pregnancies. Through the use of a case study methodwe were able to generate data which adressed research questions.This enabled us to pick issues highlighted in explicit detail and also capture the dynamics and contours of people's actions (through interactions) .Qualitative methodology in this study contributed to an inductive, emergent, interpretive and naturalistic approach to the study of people, cases, social situations, occurrences and processes in their natural settings and this revealed the significances that people attach to their experiences with early teenage pregnancies and teenage health education in schools (Yilmaz, 2013).We used an Interpretivist philosophy, Where were able to capture participants' views. Thus We chose to interview stakeholders who include; Education Officers, School Heads Teachers and Parents. We also coducted Focus Group Discussions with form one to six learners, Interviews with parents and stakeholders and Questionarres were used.Interpretivists assert that reality can be deeply understood through subjective (Yin, 2006). Saunders, Lewis, and Thornhill (2009) buttresses that the study of phenomena in their natural environment is critical to the interpretivist philosophy. Interview proceedings were recorded in verbatim,transcribed and sent back to participants,before data analysis usingthe thematic content approach.

\section{Presentation of Results}

\subsection{Culture Restricts Teachers from Engaging Teenagers in Teenage Sexual Health Education}

A question which sought to find out which environment was best to engage teenagers for teenage Sexual Health Education was posed to participants during the study. Responses from participants indicated that, whilst teachers seemedto be in control of their teaching environment, they seemed to be restricted from engaging teenagers in Sexual Health Education effectively by some held and lived cultural beliefs. Schools in Zimbabwe seem most inclined to teaching abstinence only type of Sexual Health Education. This adversely affects service delivery and has a detrimental effect on the quality of teaching Sexual Health Education in schools. In most African communities, talking about sex with young people, particularly girls, is viewed as indecent, dangerous, unacceptable and a taboo (Mukomaet al, 2009). 
A question was asked on how teachers accommodate issues of culture and religion impacted on Sexual Health Education in schools.Participants reasoned that culturally, the mere mention of Sexual Health Education attracted rebuke from parents and members from the community where teachers served. In addition to that some parents are into various church denominations which do not encourage teenagers to know or discuss issues on Sexual Health Education. Doing so was likely to encourage teenagers to fall in love and lose track of life. In other cultures, male teachers should not engage female learners in areas like teenage Sexual Health Education as this was believed to be a driver for teenagers to be eager to put to practice what they would have learnt.

\subsection{Child Headed Families a Breeding Zone for Early Teenage Pregnancies}

Svanemyret al (2014) in their Ecological Theory argue for the creation of a good environment which reflects a set of interrelated conditions legal, political, social, and cultural, among others that can effectively impact the capacity of teenagers to lead healthy lives and easily gain access to relevant and necessary health care services, information, and facilities. The same scholars argue that for an enabling environment to be created, there is need for a holistic approach in addressing wide structural elements which are beyond the persons that are crucial to shaping health education results as well as other aspects of health and development. Deriving from this theory participants were asked the reasons why teenage pregnancies seem to be on the increase in Mzilikazi District. Responses received on this question link increase in teenage pregnancies to child-headed families, poor economic performance in Zimbabwe and the generation gap.

It emerged that participants linked most teenage pregnancies to child-headed families, where teenagers would be left to take care of siblings whilst parents leave the country for greener pastures as the economic situation in Zimbabwe was deteriorating. To complement their earnings at times both parents join the great trek to foreign lands at times without documentation making it difficult for them to frequently visit and monitor their children back home. It was also revealed that some parents out of love or ignorance, would give a lot of money and groceries to their children back home and only to find that too much money or groceries would make teenagers get carried away. Captured below are some of the responses received from participants:

- FGD1P1: We have some child headed families and some children who have been incorporated into some families, for example in my case I am looking after my younger brother's three children and the eldest, a girl is turning 17 years. She has developed a culture of lying and coming back home late despite the fact that she has money for commuting and our neighbour's daughter who is in the same class with her always comes back from school earlier than her.

- NGO staffer 1: Quite a number of issues could be contributing to early teenage pregnancies in our locality. These can range from child headed families, poor guidance since most children are being left in the custody of neighbours as parents have gone to other countries in search for work. The other factor could be socializing, too much freedom on the part of children, they now know their rights than what can happen to their bodies if they engage in premarital sex.

- FGD 1 P2: The current economic challenges bedeviling the country put families and children in dilemma, teenagers can be forced to accept or be used for experiment. Teenagers can go to any extent to get what they want, even if it means having sex in exchange for money.

Issues emerging from this discussion are poverty leading to parents leaving the country to look for work in foreign countries leaving the girl child under the watchful eyes of their neighbours who at times may have failed to guide their own children. In situations where parents fail to secure jobs and any means of income teenagers are coerced into activities that threaten their future like having sex in exchange for money hence increasing chances of early teenage pregnancies.

\subsection{Teachers Lack Knowledge and Are Not Accommodative When Engaging Learners on Sexual Health Education}

Learners were asked whether Sexual Health Education was an effective way to control early teenage pregnancies.

The following are some of the responses which were captured.

- Lr 1 sch 1: Some teachers do not even know the subject and stammer when they are about to engage us in deep discussions.

- Lr 2 sch 1: Male teachers are shy to engage learners on serious debates on the subject of teenage sexual health education in class.

- Lr 3 sch 3: Teachers are not passionate about teaching Sexual Health Education, and to me that does not come as a surprise, I know teachers who also have problems with their own children, for example we know of a teacher here at school who had his daughter impregnated at an early age so to expect him to engage us will be asking too much from the overburdened teacher.

- The Deputy School Head of one of the secondary schools concurred by reiterating that:

- D.H.T sch 2: We have young teachers who I can confirm have challenges in engaging learners in teenage sexual education, three of them have openly come to me and registered their discomfort in teaching Sexual Health Education and are more aligned to STEM subjects, as a school we cannot risk losing such teachers to other schools after all, our school is a STEM oriented school.

- Whilst ruling out issues of cultural beliefs that hinder teachers from freely engaging teenagers in class on Sexual Health Education programmes. In FGD 2 teachers were blamed for over socializing with learners resulting in learners losing some respect for teachers, as the following responses illuminate:

- FGD 2 P 6:Teachers are not forthcoming when it comes to learners' discipline at schools. The fact that they drink with them in pubs and over socialize with learners makes it difficult for them to engage them on a serious business on teenage Sexual Health Education within a school environment.

- FGD 2 P 9: Some teachers think it is not their duty to fully engage learners on Sexual Health Education in classes. 
- Issues emerging from this focus group discussion is the over socializing of teachers with learners outside school environments making it difficult for teachers to engage learners on life saving skills in class. This could be attributed to the fact that learners after having socialized with some teachers are better equipped to challenge teachers basing on weaknesses inherent in teachers' social lives.

- However, some participants especially from the education fraternity bemoaned societies over expectation of teachers to assume the role of parents yet parents and community members folded their hands watching teenagers' future being eroded.

- $\quad$ FGD 2 P 8: The challenge is that we expect teachers to discipline teenagers at school yet we do not also take necessary steps to curb unbecoming behaviour each time we see or observe teenagers misbehaving. Society should shun bad behaviour all the time.

\subsection{Poor Communication between the Schools and Parents on Sexual Health Education Programmes Offered in Schools}

A question was asked seeking to find out the challenges stakeholders were facing in trying to curb early teenage pregnancies in Mzilikazi District. The researchers felt participants despite having touched on some issues of concern were not coming out clear on what other challenges schools were facing. Captured below are some issues raised by participants:

- FGD2 P 1: I once took my son for counselling to school after having noticed a sudden change of behaviour. The response I was given made me to leave the school premises without having been assisted to solve the problem which had brought me to the school.

- P 3: I attribute the increase in teenage pregnancies to lack of cooperation between parents and the schools in that at times learners leave home on the pretext that they are going to school for what are called off sessions. Since all parents want their children to pass, we cannot stop them from going back to school for off session lessons, what we do not know is that our children do not get to the school but divert to their colleagues' homes where the unthinkable happens.

- $\quad \operatorname{Tr} 2$ sch 1: The problem of teenage pregnancies needs to be looked at from four different angles: the teenagers, the parents, the community where they leave and the school environment. Just pointing fingers at teachers and not blaming the teenagers and their parents will not solve the issue. We engage the teenagers all the time but some teenagers are habitual, serial sexual athletes some of whom have been expelled from various schools before finding their way to the school they are currently enrolled now.

- $\quad \operatorname{Tr} 1$ sch 3: Parents do not monitor their children and at times give them too much freedom, they do not make any follow ups on what their children have learnt at school even to ask what challenges the children have faced during the course of the day.

- Issues emerging from the above responses link early teenage pregnancies to poverty and poor communication between school authorities and parents. The issue raised by the School Head of how some parents, driven by poverty, devised plans to sell drug laced food products to school children at school premises is of great concern. Quizzed on the topic of learners buying food laced with drugs the school head indicated that most of the learners who bought such foodstuffs knew it was laced and were no longer simple customers but advocates for drug laced foodstuffs within school premises.

\section{Conclusions}

- The subject curriculum is not readily available for use in the schools, save for GBV which is now an examinable subject.

- Content in most subjects linked to Sexual Health Education are poorly organized and lack coherence of the subject matter. Consequently, the teachers fail to match the sequence. Added to this, time allocated for the subject in the school time table is not adequate enough to impact on behaviour change.

- There is lack of job training and professional development for the teachers. It is assumed that all teachers have knowledge on Sexual Health Education, yet the new curriculum is not known by the majority of the teachers. Added to that, there is no comprehensive syllabus available for easy use by teachers. Subject delivery is therefore ineffective because of lack of induction and teacher expertise in the subject matter.

- Cultural practices in communities and the school set up have an impact on quality education of the subject. It was revealed that the teachers felt embarrassed to discuss about sex with their learners. Most parents did not want their children to be taught about sex matters during what they perceived as early years since they take it as a taboo. In such a scenario, teachers found it extremely hard to effectively educate their learners on the subject.

- It also emerged that teachers lack time to engage learners on Sexual Health Education because they are preoccupied with other subjects deemed as core or important subjects. Subjects like mathematics, science and Engineering (STEM) most favoured by industry.

\section{Recommendations}

- The Ministry of Primary and Secondary Education should facilitate human capital development programmes for capacity building, in this respect, teachers and School heads can be called to attend refresher courses or workshops to receive updates on trends and challenges emerging.

- There is need for awareness programmes on early teenage pregnancies spearheaded by teachers and learners.

- Learners can be given a chance to interact with single mothers who fell pregnant and are regretting the missed opportunities forgone in learning, this helps teenagers to know and accept the realities of life. 
- Each school should have a Sexual Health Education resource teacher who is fully trained in the subject area.

\section{References}

i. Bandura, A. (1977). Social Learning Theory. Englewood Cliffs, NJ: Prentice Hall.

ii. Creswell, J. W. (2013). Qualitative inquiry and research design: Choosing among five approaches (3 ${ }^{\text {rd }}$ ed.). Thousand Oaks, CA: Sage.

iii. Creswell, J. W. (2014). Research Design: Qualitative, Quantitative, and Mixed Methods Approaches. (3 ${ }^{\text {rd }}$ Ed.). Thousand Okas, CA: Sage.

iv. Denscombe, M. (2007). The Good Research Guide for small-scale social research projects.3rd ed. London: Open University Press.

v. Denscombe, Martyn (2008). Communities of Practice A Research Paradigm for the Mixed Methods Approach. Journal of Mixed Methods Research 2 (3): 270-283.

vi. Giami, A., Ohlrichs, Y., Quilliam, S., Wellings, K., Pacey, S., Wylie, K.R., (2006). Sex education in schools is insufficient to support adolescents in the 21st century. Sexual \& Relationship Therapy 21 (4), 485-490.

vii. Goldstein, R (2017). Sexual Health Education: A Comparison between Denmark and The United States, University: University of Copenhagen.

viii. Hayes RJ, Moulton LH: Cluster randomized trials. 2009, Boca Raton, Florida: Chapman \& Hall

ix. Holstein, J. A. (Eds.). (2002). Handbook of Interview Research: Context and Method. Thousand Oaks, CA: Sage.

X. Kirby D, Obasi A, Lans B.A (2006) The effectiveness of sex education and HIV education intervention in schools in developing countries in Ross D.A, Dick B, Fergurson J. Editors 103-150 Preventing HIV/AIDS in young people a systematic review of evidence from developing countries.

xi. Kirby D. (2007). Emerging Answers. Washington, DC: National Campaign to Prevent Teen Pregnancy, 2007.18. Office of Adolescent Health. 'Evidence-Based Programmes (31 Programmes). Accessed March 5, 2018, from http://www.hhs.gov/ash/oah/oah-initiatives/teen_pregnancy/db/programmes.html, Accessed 06/06 /2018

xii. Ministry of Education, Sport, Arts and Culture, (2012) Life Skills, Sexuality, HIV and AIDS Education Strategic Plan, 2012-2015, Harare, Zimbabwe: Ministry of Education, Sport, Arts and Culture.

xiii. Ministry of Education, Sport, Arts and Culture, (2012) Ministry of Health and Child Welfare, National Adolescent Sexual and Reproductive Health Strategy, 2010-2015, Harare, Zimbabwe: United Nations Population Fund (UNFPA), UNICEF and WHO

xiv. Ministry of Health and Child Welfare (2009), National Adolescent Sexual and Reproductive Health Strategy, 2010-2015, Harare, Zimbabwe: United Nations Population Fund (UNFPA),

xv. Ministry of Health and Child Welfare, (2012) National Sexual and Reproductive Health Stategy, Harare, Zimbabwe: Ministry of Health and Child Welfare.

xvi. Morrell R, Epstein D, Unterhalter E, Bhana D, Moletsane R (2009) Towards gender equality. South African schools during the HIV and AIDS epidemic. Pietermaritzburg: University of Kwa-Zulu Natal Press. pp. 27-52

xvii. Mukoma, W. (2001). Rethinking School-Based HIVIAIDS interventions in South Africa. South African Journal of Child and Adolescent Mental Health, 13(1):55-62.

xviii. R. Naz, 'Sex education in Fiji,' Sexuality and Culture, vol. 18, no. 3, pp. 664-687, 2014.

xix. Rani M, Lule E. Exploring the socioeconomic dimension of adolescent reproductive health: a multicountry analysis. Int Fam Plan Perspect2004;30:110-7.doi:10.1363/3011004 United Nations Population Division.

xx. Rasanathan K, Damji N, Atsbeha T, et al. Ensuring multisectoral action on the determinants of reproductive, maternal, newborn, child, and adolescent health in the post-2015 era. BMJ2015:h4213.doi:10.1136/bmj.h4213

xxi. Remez L, Woog, V. and Mhloyi, M, (2014) Sexual and reproductive health needs of adolescents in Zimbabwe, In Brief, New York: Guttmacher Institute, No. 3.

xxii. Saunders, M., Thornhill, A. and Lewis, P. (2016). Research methods for business learners. $7^{\text {th }}$ Edition. London: Pearson Education.

xxiii. Singh, S., Bankolea, A. And Wooga, V. (2006). Evaluating the need for sex education in Developing countries: sexual behaviour, knowledge of preventing sexually transmitted infections/HIV and unplanned pregnancy. Sex Education: Sexuality, Society and Learning 5(4), 307-331.

xxiv. Uganda Bureau of Statistics (UBOS): Statistical Abstract June 2012. 2012, Kampala, Uganda: Uganda Bureau of Statistics

xxv. United Nations,Deparetment of Economic and Social Affairs. Sustainable development goals: SDG indicators. Available: https://unstats.un.org/sdgs/metadata/?Text=\&Goal=17\&Target= [Accessed 20 Oct 2019 